\title{
Management of hyperglycemia in oncological patients scheduled for an FDG-PET/CT examination
}

\author{
Laura Evangelista $^{1} \cdot$ Stefania Gori $^{2} \cdot$ Giuseppe Rubini $^{3} \cdot$ Marco Gallo $^{4}$
}

Published online: 28 October 2019

(c) Italian Association of Nuclear Medicine and Molecular Imaging 2019

Positron-emission tomography combined with X-ray computed tomography and using $\left[{ }^{18} \mathrm{~F}\right]$-fluorodeoxyglucose (FDG-PET/CT) is being used for staging, restaging, followup, and treatment monitoring of several glucose avid tumors. Since FDG and glucose compete for the same transporters and for hexokinase, hyperglycemia may significantly modify the value of the semi-quantitative variables commonly used for estimating the uptake of FDG, including the standardized uptake value (SUV). Therefore, this issue is of particular relevance, when FDG-PET/CT is used in patients with poorly controlled diabetes mellitus. Thus, because of the competition between FDG and glucose, the control of glycemia may be relevant when imaging is being pursued, with the use of SUV, to estimate the degree of malignancy during the staging of the tumor and in particular for the comparison during follow-up and in case of therapy monitoring. Indeed this issue has been considered, since PET with FDG was in the early phase of introduction into clinical practice about 40 years ago.

In spite of the acknowledgement of this very relevant issue, demonstrated by a simple PubMed search using the

This paper represents the opinion of the "AIMN-AMD-AIOM Diabetes and Cancer working group" members: Silvia Acquati, Gennaro Clemente, Romano Danesi, Stella D'Oronzo, Laura Evangelista, Daniele Farci, Pietro Ferrari, Marco Gallo, Marisa Giorgini, Valerio Napoli, Gabriella Piscitelli, Antonio Russo, Matteo Salgarello.

Laura Evangelista

laura.evangelista@unipd.it

1 Nuclear Medicine Unit, Department of Medicine - DIMED, University of Padua, Via Giustiniani, 2, 35100 Padua, Italy

2 Oncology Department, IRCCS Sacro Cuore Don Calabria, Negrar, Verona, Italy

3 Nuclear Medicine Unit, University of Bari “Aldo Moro", Bari, Italy

4 Oncological Endocrinology Unit, Department of Medical Sciences, University of Turin, AOU Città della Salute e della Scienza di Torino, Turin, Italy terms "FDG PET" and "blood glucose levels" and "FDG PET" and "hyperglycemia" that allowed to retrieve more than 200 articles, there is only a limited number of papers dealing with the practical procedure to be used in case of hyperglycemia in oncological patients undergoing an FDGPET/CT examination.

The aim of this paper is to provide a practical guidance for the management of hyperglycemia, either due to diabetes mellitus or other causes, in oncological patients scheduled for FDG PET/CT, to optimize the preparation for the exam and increase the reliability of the semi-quantitative assessment of FDG uptake in tumor.

The Society of Nuclear Medicine and Molecular Imaging (SNMMI) guidelines recommend rescheduling of the scan when glycemia is above $150-200 \mathrm{mg} / \mathrm{dL}$ [1]. The European Association of Nuclear Medicine and Molecular Imaging (EANMMI) guidelines suggest that FDG PET/CT study should be rescheduled, if glycemia is higher than or equal to $200 \mathrm{mg} / \mathrm{dL}$ [2]. Both guidelines suggest that pre-scan hyperglycemia may be reduced by administration of rapid-acting insulin. However, the EANM guidelines consider also the impact of longer acting insulin and recommend specific time intervals for the administration of the different types of insulin prior to scan. The inconsistency between different guidelines, which originates from lack of robust and credible evidence, has resulted in a diverse range of accepted pre-scan glycemia levels in clinical PET imaging. In a web-based survey of PET/CT users, specialists from 128 PET centers worldwide responded to the question regarding the pre-scan glycemia cutoff used at their institutes [3]. Cutoff values varied from 150 to $250 \mathrm{mg} / \mathrm{dL}(8.3-13.9 \mathrm{mmol} / \mathrm{L})$ and $7 \%$ of the sites used no cutoff. Based on the recent systematic review and meta-analysis by Eskian et al. [4], patients who are still hyperglycemic after at least $4 \mathrm{~h}$ of fasting would have significantly lower FDG uptake in the brain and muscles and significantly higher FDG uptake in the liver and mediastinal blood pool in comparison with euglycemic patients. However, pooled findings reported that glycemia levels 
do not have any apparent significant effect on FDG uptake by tumors. Considering the lack of significant correlation between glycemia and FDG uptake in tumors, Eskian et al. recommend no interventions for hyperglycemic patients who are scheduled to undergo PET scan, except under two conditions: glycemia $>200 \mathrm{mg} / \mathrm{dL}$, or when the liver is the area of interest [4]. In this latter condition, FDG uptake significantly increases in liver during hyperglycemia, therefore patients should be kept euglycemic (glycemia $\leq 110 \mathrm{mg} / \mathrm{dL}$ ), when liver assessment is required, to prevent decreased tumor-tobackground uptake ratios.

There are other important issues about the management of patients with diabetes and who are scheduled to undergo PET/CT scan for oncological requests. First, pre-hydration is important to favor the elimination of FDG in the bladder, to reduce artifacts and for radiation safety reasons, the consumption of $1 \mathrm{~L}$ of water in the $2 \mathrm{~h}$ preceding the FDG administration is recommended, regardless of the presence of diabetes. Second, any infusion used for intravenous prehydration should not contain glucose.

By taking into account the most recent papers dealing with this issue, based on large number of patients (Table 1) and the guidelines issued by the SNMMI, as well as those of the EANMMI, some frequently asked questions are addressed below.

1. What is the acceptable glycemia for FDG-PET/CT scan?

In case of total body FDG PET/CT examination, glycemia should be lower than $200 \mathrm{mg} / \mathrm{dL}$; if higher, the FDG-PET/CT study should be rescheduled; otherwise, specific interventions should be implemented to lower the glycemia levels. However, the current recommendation for brain PET/CT is to limit FDG administration to patients with glycemia $<160 \mathrm{mg} / \mathrm{dL}$ [5]. It has been demonstrated that brain imaging in healthy volunteers with hyperglycemia may reveal patterns that are similar to those found in neurodegenerative diseases [6].

2. What is the correct preparation before an FDG-PET/CT scan in patients with diabetes treated with anti-diabetic agents other than insulin?

In patients with type 2 diabetes treated with oral anti-diabetic agents, FDG-PET/CT should preferably be performed late in the morning. Moreover, to reduce the cross reaction with the intravenous contrast agent and the physiological uptake of FDG in the bowel, metformin should be discontinued at least $48 \mathrm{~h}$ before the procedure [7], especially in patients with a suspected or known malignant abdominal disease. No evidence is available about sulfonilureas, glinides, alpha-glucosidase inhibitors, DPP-4 inhibitors, SGLT2-inhibitors, and GLP-1 receptor agonists, whereas preliminary evidence suggests that pioglitazone may have increased the uptake of FDG by malignant lesions [8].

3. What is the correct preparation before an FDG-PET/CT scan in patients with diabetes treated with insulin?

In patients with type 1 diabetes, as well as in patients with type 2 diabetes treated with insulin, an FDG-PET/ CT study can be scheduled at different hours of the day, suggesting different approaches for the preparation:

a. In case of FDG-PET/CT performed early in the morning, particular attention should be given to the type of insulin. In case of long-acting insulin administered the evening before the exam, there might be a slight interference with the FDG-PET/CT study. Thus, if early morning is the preferred time for the examination, intermediate-acting (instead of longacting) insulin should be recommended the day before the examination. Thereafter, these patients should have a normal breakfast and restart with the daily amount of insulin.

Table 1 Selected studies about hyperglycemia and FDG PET/CT examination

\begin{tabular}{|c|c|c|c|c|}
\hline References & $\begin{array}{l}\text { Year of } \\
\text { publica- } \\
\text { tion }\end{array}$ & Type of article & No.of pts & Outcome of interest \\
\hline Kaneta et al. [10] & 2006 & Original article & 159 & The influence of fasting and hyperglycemia on myocardial FDG uptake \\
\hline Janseen et al. [11] & 2010 & Original article & 30 & $\begin{array}{l}\text { The impact of glycemia on PET-based treatment response prediction in } \\
\text { rectal cancer }\end{array}$ \\
\hline Kubota et al. [12] & 2011 & Original article & 70 & The effect of glycemia on FDG liver uptake \\
\hline Lindholm et al. [13] & 2013 & Original article & 500 & The influence of glycemia on the FDG uptake in normal organs \\
\hline Niccoli-Asabella et al. [14] & 2013 & Review & 13,063 & $\begin{array}{l}\text { The screening at the preliminary visit and a subsequent good preparation of } \\
\text { the patient before scheduling can reduce hyperglycemic status }\end{array}$ \\
\hline Khandani et al. [15] & 2016 & Original article & 117 & The frequency of glycemia $>150 \mathrm{mg} / \mathrm{dL}$ in patients without diabetes \\
\hline Sprintz et al. [16] & 2017 & Review & 2714 & The influence of glycemia on the FDG uptake in normal organs \\
\hline Sprintz et al. [17] & 2018 & Original article & 5623 & The influence of glycemia on the FDG uptake in normal organs \\
\hline Eskian et al. [4] & 2019 & Review & 20,807 & To evaluate the effect of glycemia on SUV (standardized uptake value) \\
\hline
\end{tabular}


b. In case of FDG-PET/CT performed late in the morning or at mid-day, the patient should have a normal breakfast early in the morning (around 7.00 a.m.) and receive the usual dose of insulin. FDG should be administered at least $4 \mathrm{~h}$ after the subcutaneous injection of rapid-acting insulin or $6 \mathrm{~h}$ after the subcutaneous injection of usual short-acting insulin. An FDG-PET/CT study should not be performed on the same day of the administration of intermediate-acting and/or long-acting insulin.

4. How to manage patients treated with continuous insulin infusion?

In patients treated with continuous insulin infusion, FDG PET/CT scan should be scheduled early in the morning. The insulin pump should be switched off at least $4 \mathrm{~h}$ before FDG administration. The patient can have breakfast after the FDG PET/CT study and restart the continuous insulin infusion.

5. What is the correct preparation before an FDG-PET/CT scan in patients with diabetes on artificial nutrition?

Both parenteral nutrition and intravenous administration of fluids containing glucose should be discontinued at least $4 \mathrm{~h}$ before FDG administration.

6. How to manage a patient with diabetes and with a glycemia $>200 \mathrm{mg} / \mathrm{dL}$ ?

Reduction of glycemia by administration of rapid-acting insulin can be considered, but FDG-PET/CT study could also be postponed depending on the type and route of insulin administration. Unnecessary interventions aimed at lowering glycemia are sometimes both time and resources consuming, including insulin injection, also with a potential decrease of PET/CT scan sensitivity due to a greater muscle uptake of FDG [9]. Therefore, the examination should be postponed, whenever possible. However, some procedures can be adopted:

- The patient should be asked to walk and to hydrate, rechecking glycemia periodically until an acceptable level has been achieved;

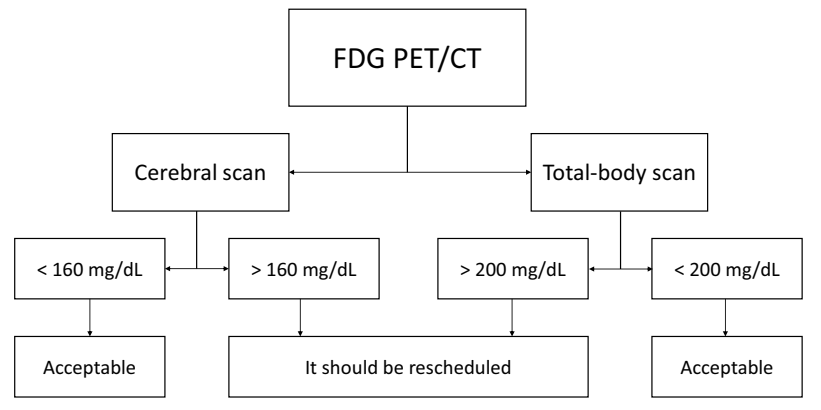

Fig. 1 A flow chart for the management of patients candidates to FDG PET/CT scan, in accordance with glycemia levels

- A subcutaneous injection of a rapid-acting insulin should be preferred, while regular insulin, intermediate-acting, or long-acting insulin are not recommended.

7. How to manage patients with drug-induced or tumorinduced hyperglycemia?

Drug and tumor-induced hyperglycemia should be managed as previously reported, rescheduling the scan or administering rapid-acting insulin. The withdrawal of treatments (e.g., corticosteroids and chemotherapy) should be avoided and a discussion with the oncologist and diabetologist is strongly recommended. The above-mentioned concepts are summarized in Fig. 1 and Table 2.

\section{Conclusions}

The measurement of glycemia before an FDG-PET/CT procedure is key for a good quality of the examination, thus, to balance the clinical needs and the quality of images, carefully selected strategies, tailored for each patient, should be sought.
Table 2 Scheduled times for FDG PET/CT exams in diabetic patients

\begin{tabular}{lll}
\hline Time & Oral anti-diabetic agents & Insulin \\
\hline Early morning & Not recommended & $\begin{array}{c}\text { 1. An intermediate insulin is rec- } \\
\text { ommended the day before exam }\end{array}$ \\
& $\begin{array}{c}\text { 2. In case of continuous infusion, } \\
\text { it should be stopped 4 h before }\end{array}$ \\
Late morning & A short-acting insulin is preferred \\
\hline
\end{tabular}

${ }^{a}$ In case of metformin, it should be withdrawal $48 \mathrm{~h}$ before examination 


\section{Compliance with ethical standards}

Conflict of interest The authors declare that they have no conflict of interest.

Human and animal rights This article does not contain any studies with human participants or animals performed by any of the authors.

Informed consent For this type of study informed consent is not required.

\section{References}

1. Delbeke D, Coleman RE, Guiberteau MJ, Brown ML, Royal HD, Siegel BA et al (2006) Procedure guideline for tumour imaging with 18FFDG PET/CT 1.0. J Nucl Med. 47:885-895

2. Boellaard R, Delgado-Bolton R, Oyen WJ, Giammarile F, Tatsch $\mathrm{K}$, Eschner W et al (2015) PET/CT: EANM procedure guidelines for tumour imaging: version 2.0. Eur J Nucl Med Mol Imaging. 42:328-354

3. Beyer T, Czernin J, Freudenberg LS (2011) Variations in clinical PET/CT operations: results of an international survey of active PET/CT users. J Nucl Med 52:303-310

4. Eskian M, Alavi A, Khorasanizadeh M, Viglianti BL, Jacobsson H, Barwick TD et al (2019) Effect of blood glucose level on standardized uptake value (SUV) in 18F- FDG PET-scan: a systematic review and meta-analysis of 20,807 individual SUV measurements. Eur J Nucl Med Mol Imaging 46:224-237

5. Varrone A, Asenbaum S, Vander-Borght T, Booij J, Nobili F, Nagren K et al (2009) EANM procedure guidelines for PET brain imaging using $\left[{ }^{18} \mathrm{~F}\right] \mathrm{FDG}$, version 2. Eur J Nucl Med Mol Imaging 36:2103-2110

6. Kawasaki K, Ishii K, Saito Y, Oda K, Kimura Y, Ishiwata K (2008) Influence of mild hyperglycemia on cerebral FDG distribution patterns calculated by statistical parametric mapping. Ann Nucl Med 22:191-200

7. Bybel B, Greenberg ID, Paterson J, Ducharme J, Leslie WD (2011) Increased F-18 FDG intestinal uptake in diabetic patients on metformin: a matched case-control analysis. Clin Nucl Med $36: 452-456$
8. Han Y-H, Kwon SY, Kim J, Na CJ, Choi S, Min J-J et al (2015) A phase II clinical trial to investigate the effect of pioglitazone on 18F-FDG uptake in malignant lesions. EJNMMI Res 5:50

9. Zhao S, Kuge Y, Tsukamoto E, Mochizuki T, Kato T, Hikosaka K et al (2001) Effects of insulin and glucose loading on FDG uptake in experimental malignant tumours and inflammatory lesions. Eur J Nucl Med 28:730-735

10. Kaneta T, Hakamatsuka T, Takanami K, Yamada T, Takase K, Sato A et al (2006) Evaluation of the relationship between physiological FDG uptake in the heart and age, blood glucose level, fasting period, and hospitalization. Ann Nucl Med 3:203-208

11. Janssen MHM, Öllers MC, van Stiphout RGPM, Riedl RG, van den Bogaard J et al (2010) Blood glucose level normalization and accurate timing improves the accuracy of PET-based treatment response predictions in rectal cancer. Radiother Oncol 95:203-208

12. Kubota K, Watanabec $\mathrm{H}$, Muratac $\mathrm{Y}$, Yukihiro M, Itoa K, Morooka M et al (2011) Effects of blood glucose level on FDG uptake by liver: a FDG-PET/CT study. Nucl Med Biol 38:347-351

13. Lindholm H, Brolin F, Jonsson C, Jacobsson H (2013) The relation between the blood glucose level and the FDG uptake of tissues at normal PET examinations. EJNMMI Res 3:50

14. Niccoli-Asabella A, Iuele FI, Merenda N, Pisani AR, Notaristefano A, Rubini G (2013) 18F-FDGPET/CT: diabetes and hyperglycaemia. Nucl Med Rev Cent East Eur 16:57-61

15. Khandani AH, Bravo IM, Patel PS, Ivanovic M, Kirk D (2017) Frequency of high blood glucose prior to FDG PET. AbdomRadiol. 42:1583-1585

16. Sprinz C, Altmayer S, Zanon M, Watte G, Irion K, Marchiori E et al (2018) Effects of blood glucose level on 18F-FDG uptake for PET/CT in normal organs: a systematic review. PLoS ONE 13:e0193140

17. Sprinz C, Zanon M, Altmayer S, Watte G, Irion K, Marchiori E et al (2018) Effects of blood glucose level on 18F fluorodeoxyglucose (18FFDG) uptake for PET/CT in normal organs: an analysis on 5623 patients. Sci Rep 8:2126

Publisher's Note Springer Nature remains neutral with regard to jurisdictional claims in published maps and institutional affiliations. 